\title{
Design and Research on the Teaching Method of C Language Course Retaking in College
}

\author{
Kene Li, Jin Yang \\ School of Electrical and Information Engineering \\ Guangxi University of Science and Technology \\ Liuzhou, China \\ e-mail: likene@163.com
}

\author{
Jianqin $\mathrm{Xu}^{*}$ \\ Engineering training center \\ Guangxi University of Science and Technology \\ Liuzhou, China \\ e-mail: gxutxjq@126.com
}

\begin{abstract}
This research aims to present a way for teachers to teach course-retaking classes of " $\mathrm{C}$ Language Programming" effectively. For study purpose, this research investigated the course-retaking students by applying a pre-course questionnaire, and then discussed and analyzed the students' study problems which led to their failure to pass the course examination. Based on the survey results, this research presented a supervisionfeedback-based interactive teaching method which was divided into three parts: guiding introductory, interactive discussion, and feedback exercises. Therefore, the basic knowledge points were mentioned several times, and thus, were strengthened greatly. The statistic data show an increase in attendance rate with the class times. Furthermore, the teaching quality analysis based on the post-assessment questionnaire and the study results reveals the correlation between usual performance and final exam. It is concluded that the teaching methods improve student learning performance and outcomes.
\end{abstract}

Keywords-course retaking; C language; interactive; teaching method; feedback; attendance rate

\section{INTRODUCTION}

With the popularization of higher education, the recruitment scale of higher education institutions keeps expanding, and the levels of citizens' education have been continuously improved [1-3]. However, while the number of colleges and universities and the number of students have grown rapidly, the student-quality of higher education recruitment has been declining year by year. Due to the difference in the batches of higher education recruitment in China, the colleges of second-batch student-recruitment are more affected by China's higher education expansion policy, in addition to the decreasing actual total number of national higher education entrance examination [1-3]. Under the pressures of these two factors, the quality of students in the colleges further declines. In order to effectively remedy the occurrence of this phenomenon, it is a better solution to set up retaking courses under the condition of meeting the requirements of separating classes [4]. Therefore, how colleges should be positioned and how the quality of education can be improved are important issues for college teachers to keep up with the times. This paper focuses on the design and research of teaching methods about $\mathrm{C}$ language programming retakingcourse.

Sponsor: A project of higher education undergraduate teaching reform in Guangxi in 2017, "Research on inquiry teaching mode of electronic technology course and cultivation of students' application ability" ( item no: 2017 jgb 292 ).
Due to the difference from common students, the teaching methods used must be fully in consideration of the characteristics of retaking students. In the era of mass education in today's China higher education, the environment and ideology of college students have undergone major changes. Social temptations have emerged in an endless stream. In particular, the bad habits of hedonism are more likely to be delivered by various channels such as the media, public opinion, and social networks, and then, influence and change the social awareness of college students. It has seriously affected the ideology of college students and made them unwilling to spend time learning. Moreover, the colleges are greatly restricted in all aspects such as institution construction, hardware facilities, faculty resources, and quality of students. In addition, the college students generally lack the motivation for learning and have poor learning autonomy [1-3]. Therefore, it is necessary to analyze and design the teaching method according to the students' characteristics to resume students' lost enthusiasm for learning. Based on the special situation of course-retaking students, this paper proposes a supervisionfeedback-based interactive teaching method to teach effectively. This teaching method emphasizes on content teaching, teacherstudent dialogue and learning promotion, in the hope that it can't only complete the teaching of the course content better, but also promote students' interest in learning and improve teaching quality.

\section{Exploration of TEACHING Methods}

"C Programming Language" is a fundamental course required all for electrical engineering majors. In order to formulate an effective teaching plan according to the actual situation of the students in the course-retaking class, the authors conducted a pre-course questionnaire survey of the students in the early stage of the class to try to find out the main factors affecting the quality of the classroom teaching, and then to explore an effective teaching method in consideration of these factors. Through the analysis of the survey results, we learned that the basic situation of the students in the class is as follows:

Firstly, the students' interest in the course "C language programming" is not high, but the students still hope to acquire knowledge through classroom teaching to pass the exam. The data analysis results showed that $68 \%$ of the students were not interested in the course. $75 \%$ of the students did not have a positive enthusiasm for class. Another 3\% of the students were 
reluctant to attend classes. However, when asked about the learning effect, 93\% of the students thought that class-learning was better than self-study, and $68 \%$ of the students hoped to improve their C programming skills through teacher' lectures.

Secondly, the students had a certain understanding of the basic knowledge of $\mathrm{C}$ language, but their learning attitudes were not positive, and less time was spent on course study. The survey results showed that $57 \%$ of students thought that they had a certain amount of basic knowledge, such as the definition of some variables, arrays, etc. 3\% of students had a good grasp of C language, and could write a simple complete program. But $3 \%$ of students said completely NO for grasp of C language, even for the basic concepts. In terms of learning attitudes, only $7 \%$ of students conducted pre-class previews and after-class review and homework assignments. $11 \%$ of students said they had no spare-time study, even a after-class study.

Thirdly, the students had a certain expectation for improving the ability of $\mathrm{C}$ language programming. The results of the survey showed that $32 \%$ of the students did not have high requirements for the course, as long as the knowledge they learned could help them pass the exam, but $68 \%$ of the students had higher expectations of the course, for which they hoped to master the basic programming skills, and could actually apply it to the subsequent courses learning.

Through the analysis of the above findings, we can know that the students' foundation is poor and their enthusiasm for class is not high, but the majority still have the original intention to improve their programming ability by listening to teachers' lectures. Therefore, it is a good factor which can be used to strengthen the promoting for teaching, and encourage still and urge students to learn. From the survey results, we can also find that students of the course retaking are lazier in their learning attitudes, spend less time on learning, and do not want to think independently. In order to effectively eliminate this dropout mentality and reduce the number of missed classes, students' management needs to be strengthened, and a strict attendance policy needs to be established, in which the attendance rate can be directly linked to the general evaluation, so that the students' attitudes toward attending classes are changed from unwilling to unacceptable.

\section{iII. Classroom Practice of Teaching Methods}

The author applies the above-discussed teaching methods to the teaching of the $C$ language retaking course and carries out teaching practice as follows.

\section{A. Selected Examples, Refined and Practiced, and Gradually Guided}

There are fewer classes in the $\mathrm{C}$ language retaking class. If the traditional teaching method is applied by detailed explaining of each basic concept, it is difficult to complete the course in a timely manner. Moreover, this traditional indoctrination method neglects the main role of students. In addition, it also requires a student's high degree of cooperation and strong self-learning ability. From the above analysis of the students' situation, it obviously do not achieve a good teaching effect. Therefore, in the course of class, the author divides the teaching content into two parts: the basic concepts and programming. The basic concepts are composed of the basic operation methods, data types, statements and program control structure of the $\mathrm{C}$ language and the programming is mainly guided to help students better construct programming ideas independently. For the first part, the teacher shall pay attention to the basics, explain and analyze the important concepts and sentences in detail. The second part is more comprehensive, and the contend shall go from the easy to the difficult and complicated. In addition, more examples shall be analyzed.

\section{B. Combining Multimedia and Board Writing, and Stressing both Teaching and Communication}

At present, most colleges have generally integrated information technology into curriculum teaching [3]. This new type of multimedia teaching method is also widely used by teachers. Due to numerous concepts and flexible grammar structures, it is difficult for students to understand and grasp by multimedia only [5]. Therefore, in class, the author combines multimedia teaching with traditional board writing. The incomprehensible concepts are illustrated to help students grasp, and the key sentences are written on the blackboard and taught in detail. The students and teachers interact with each other. For example, when the author is teaching programming with Bubble Sort algorithm to sort numbers from big to small, four students are asked to come to the podium and given a different number of pieces of chalk, so that they can start with the chalk from the first student and all other students in sequence. Numbers are compared and exchanged when the the first student's number of chalks is smaller than others number. Cycles are repeated until the number of chalks in the hands of all students is sorted from the largest to the smallest. This way of explanation enables all students to focus on and participate in class [6]. Through this teaching method, not only the advantages of vivid multimedia teaching can be played, but also the interaction with students can stimulate the learning atmosphere in the classroom and thus enhance students' enthusiasm for learning. More importantly, it can help students master and impress them as quickly as possible.

\section{Establish an Attendance Policy and Strictly Implement the Assessment System}

Due to the laziness of students' learning attitudes in retaking class, the author has established a stricter attendance policy to improve this situation by performing attendance before each class or between classes. When the content of a class is high, the students were asked to answer questions while attending class, which not only achieved the purpose of attendance but also communicated with the students. In addition, in order to improve student attendance, it shall be declared at the first class that students whose attendance does not reach more than one-half of the total attendance will be disqualified. In order to understand students' situations more comprehensively and urge students to improve their learning attitude, the author divided the assessment into two parts: the usual grades and the final exam results. The usual grades were divided into attendance and after-school assignments. In the two parts of the scores, the results include $20 \%$ of the attendance rate, $10 \%$ of assignments, and $70 \%$ of the final grade. This assessment method design not only reflects the student's usual performance and comprehensive level, but also helps improving the teaching quality. 
TABLE I. ATtENDANCE RATE OF THE RET AKING COURSE

\begin{tabular}{|c|c|c|c|c|c|c|c|}
\hline Class Times & $\mathbf{1}$ & $\mathbf{2}$ & $\mathbf{3}$ & $\mathbf{4}$ & $\mathbf{5}$ & $\mathbf{6}$ & $\mathbf{7}$ \\
\hline $\begin{array}{c}\text { Attendance } \\
\text { rate }\end{array}$ & $82 \%$ & $60 \%$ & $69 \%$ & $64 \%$ & $73 \%$ & $80 \%$ & $84 \%$ \\
\hline
\end{tabular}

\section{Teaching Quality Analysis}

In order to test the validity and feasibility of the teaching methods explored in this paper, the author analyzes the teaching quality from the following aspects and evaluates the teaching methods.

\section{A. Effect Evaluation on Post-Assessment Questionnaire}

After the entire $\mathrm{C}$ language course retaking teaching, as well as the analysis of the results of the questionnaire survey conducted before the beginning of the course, in order to obtain effective feedback and students' opinions and suggestions on the course, the author designed a post-assessment questionnaire. The survey results analyze the teaching quality from the following aspects.

First of all, students' interest in C programming has improved and their learning attitude has become more positive. The survey results showed that $16 \%$ of the students had a greater interest in C programming, and 94\% of the students said that it was necessary to study in the classroom. A student mentioned that "When I first learned C language courses, I felt very difficult to learn, and almost did not understand what the teacher said. But after this retaking class, I felt that $\mathrm{C}$ language was not so difficult, and I can understand teacher had taught. Moreover, the atmosphere of the classroom is also good.” On the other hand, when we want to find out the composition of the students' grades they are expected, $11 \%$ of the students hope that the total score of the results consists entirely of final exam, and $50 \%$ of the students hoped that $70 \%$ of the scores will be final exam, and $30 \%$ will be usual grades. Compared with $22 \%$ of the students who hope that total score consists entirely of the usual grades in the previous survey, this data is gratifying. It reflects not only that the students are more positive in their learning attitude and more confident in their own knowledge, but also effectiveness of the teaching methods.

Second, the students' mastery of the C programming has been improved and they are willing to spend time on the study of the curriculum. The results of data analysis show that $59 \%$ of students have a basic understanding of the $C$ language concepts, and $30 \%$ of students can write some basic statements. When listening to comments and suggestions from the students about the course, some students said that when the first time they took C programming classes, the teacher kept talking and they couldn't understand completely. However, the teacher of the retaking paid attention to our understanding, so we had made a good progress." In addition, when $70 \%$ of the were reviewing studying of this course, they thought it is necessary to do preview, after-class review and assignments, and hoped that the teacher can give more assignments to help them consolidate what they had learned. $21 \%$ of students said that preview, review and assignments were an indispensable part of studying. They must spend more time and pay enough attention.

Finally, after learning and in-depth understanding of $\mathrm{C}$ language during this period, some students think that their independent programming ability is poor yet, and thus, the expectations for applying it to practice and solving practical problems are reduced subsequently. Although $17 \%$ of the students said that they can better grasp the content they learned after the retaking course, $52 \%$ of the students still responded, although they can basically understood when class, but they forgot about the lesson after class, which hurt their confidence greatly. However, 57\% of students expected that they could apply $\mathrm{C}$ programming to practice. Compared with the results of previous survey, it is $11 \%$ lower, which reflected that students' confidence declined due to the difficulty in grasping the programming idea despite less exclusion of $\mathrm{C}$ programming. As a results, the teacher should give more encouragement to the students' independent programming and learning in spare time, help the students turning insufficiency into motivation, and enhancing their self-motivation and self-confidence.

\section{B. Effect Evaluation on Attendance and Assignment}

During the entire retaking course, the author had 7 times students' attendance checks (with a total of eight classes, the fifth attendance check was skipped due to a large amount of class information necessary for teaching), and collated the attendance data, which can be seen in Table I.

From Table I, we can observe the students' attendance changes. Since the first attendance check is the first class of the retaking class, in the general case, the first class should be the highest attendance, but it can be seen from Table 1 that, the first students' attendance rate is not high, and the second attendance rate is not ever optimistic, even $22 \%$ lower than the former, which shows that students have little interest and enthusiasm in C programming, even the exclusionary emotions that do not want to learn or be tired of learning. This fact demonstrates the results of students' attitudes towards the retaking course in the previous survey questionnaire. However, it can be seen from Table I that after a period of the course teaching, the student's attendance rate has gradually increased, which is consistent with the results obtained in the second survey. Therefore, judging from the attendance rate change, the proposed teaching methods can improve students' enthusiasm for learning and help students develop better study habits.

Because the retaking students have one more class than other students, the study pressure is relatively larger. Therefore, the students should be given assignments with the "FEW BUT WELL CHOSEN" principle, which can't only assess the students' knowledge acquired, but also allow students to review appropriately. In this course, two assignments have been arranged. From the collated data, the average scores are 68.3 for the first assignment, and 65.4 for the second assignment, respectively. From the average scores only, it gets worse, but it has made progress from the overall situation. On the one hand, the second assignment is arranged at the end of course with more comprehensiveness, and required students' programming by themselves, compared with the first assignment with more basic concepts and easier programming. On the other hand, the completion rate of first assignment was only $67 \%$, the pass rate was $90 \%$, while the completion rate of second assignment reached $75 \%$, with a pass rate of $100 \%$. This substantiates that students' learning attitude and efficacy are improving. 


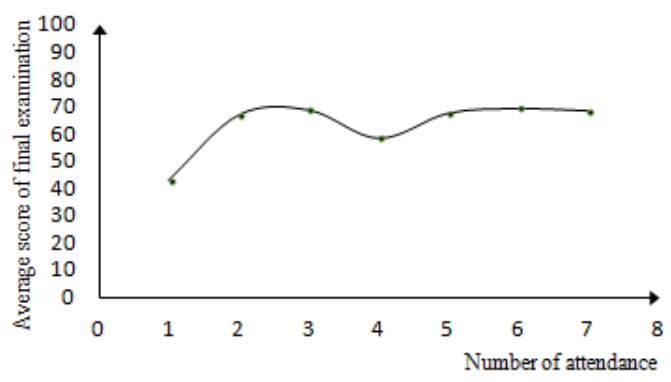

Fig. 1. Average final scores with respect to attendance times.

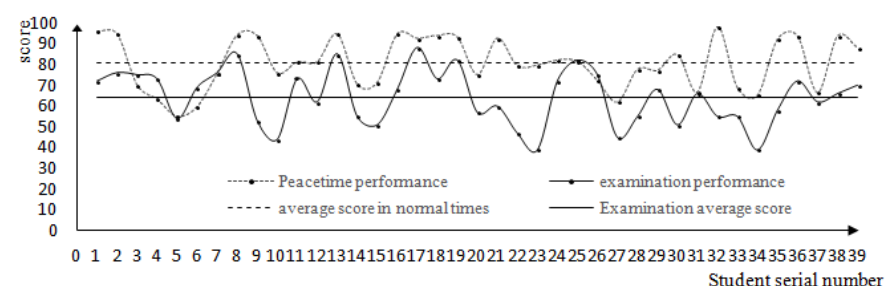

Fig. 2. Final scores and usualscores.

Based on the above analysis of the usual grades and the observation of students' classroom performance, the teaching method has improved the students' learning attitudes greatly, which is an important factor in the learning and teaching. Therefore, the student's usual performance demonstrates the teaching method is feasible. It is worth pointing out that, the usual assignments and attendance can't fully reflect the true level of the students, nor can we draw a conclusion that the students have a good and in-depth mastery of the course. For this problem solving, the authors try to assess the quality of teaching by making a correlation analysis of the usual performance and the final exam grade as follows.

\section{Analysis of the Correlation between Usual Performance and Final Exam}

This paper averages the final exam scores for the students with same actual attendance times during this retaking course, and the relationship of the average scores respect to the attendance times is given in Fig. 1. It is worth noting that, according to the attendance policy established by the authors, 7 students in the retaking class were disqualified because they had fewer than 4 attendances. In addition, 5 students had applied for exemption from class-attendance due to conflict with other courses or good feeling about mastery of this course. The course is exempt from eligibility. Therefore, the number of attendances for one, two, or three times in Fig. 1 is the attendance situation of students who had already applied for exemption from class-attendance.

From Fig. 1, it can be seen that among the students who apply for exemption, although these students have a better basis, the students attending only once have a larger gap than the other students. In addition, the other students who have not applied for exemption show a greater relationship between average grades and attendance times. However, the score of students with 4 attendances was lower compared with 3 attendances. The reason may be their poor foundations or ability to accept the knowledge. On the whole, there is a correlation between the times of attendances and the final grades, which substantiates the effectiveness of the proposed teaching methods. To further investigate the relationship between individual performance and final performance, this paper analyzes the students' usual grades (attendance and assignments) and their final scores, which can be seen in Fig. 2. By collated all the students' scores, we know that the average usual score is 80.6, and the average final score is 64.3. From the Fig. 2, it can be seen that except for a few students, the final scores of the students, whose usual scores are 90 or more, are generally more than 70 . While the students who scored 75 or less usually do not pass the final exam except for a few individuals. Therefore, it can be seen that final score and usual performance are basically positively correlated. This indicates that classroom learning can better ensure students' mastery of knowledge, and further substantiates effectiveness of the proposed teaching methods.

\section{ConClusion}

Based on the teaching research practice of this course, it is shown that the proposed teaching method in this paper for $\mathrm{C}$ programming course-retaking class is effective. To improve the quality of teaching, it is necessary to adopt the appropriate teaching methods, understand the students' characteristics, and interact with and encourage them. It also requires students to cooperate with the implementation of teaching methods and enhance their own learning initiative and self-discipline, so that students are willing to come to the classroom, participate in class, and achieve the ultimate goal of learning.

\section{REFERENCES}

[1] L. Shi, and C. Xing, China's higher education expansion and its labor market consequences, May 2010, IZA Discussion Paper No. 4974.

[2] L. Shi, J. Whalley, and C. Xing, "China's higher education expansion and unemploy ment of college graduates," China Econ. Rev. Vol. 30, pp. 567-582, 2014.

[3] Y. Zhao, and Z. Yang, “Countermeasures of Regional Undergraduate Universities before Students Recruiting Crisis,” J. Baoshan Univ. Vol. 32, No. 5, pp. 48-51, 2013. (In Chinese)

[4] J. Zhang, “On the Improvement of Make-up Curriculum Study under Cred it System,” J. Yangzhou Univ. (High. Educ. Stud. Edit.) Vol. 15, No. 6, pp. 41-44, 2011. (In Chinese)

[5] C.H.H. Tsay, A. Kofinas, and J. Luo, "Enhancing student learning experience with technology-mediated gamification: An empirical study,” Comput. Educ. vol. 121, pp. 1-17, January 2018.

[6] M.C. Vega-Hernández, M.C. Patino-Alonso, and M.P. Galindo-Villardó n, "Multivariate characterization of university students using the ICT for learning,” Comput. Educ. vol. 121, pp. 124-130, March 2018. 